\title{
Laser contact through electrosprayed alumina inverse opals on silicon
}

\author{
Arnau Coll*, Sandra Bermejo, Isidro Martin, Ramon Alcubilla. \\ Micro and Nano Technologies research group (MNT), Electronic Engineering Department, Universitat \\ Politècnica de Catalunya, Jordi Girona 1-3, Barcelona 08034, Spain \\ *Corresponding author: e-mail: arnau.coll@upc.edu
}

\begin{abstract}
In crystalline silicon (c-Si) solar cell field, an intensive effort is being paid to reduce the quantity of silicon material used in each cell in order to minimize its costs. With the reduction of wafer thickness, light trapping inside the c$\mathrm{Si}$ absorber becomes more and more necessary. Several photonic structures have been proposed underlining their optical properties. However, addressing other technological issues, like contact formation through the photonic structure, is also necessary for their application into finished devices. In this paper we study the viability of laser firing technique to create solar cell base contacts through inverse opals deposited on the previously passivated rear surface of the device as photonic light trapping structures. Firstly, we check out that electrical surface passivation properties are not degraded during the inverse opals fabrication steps. Next, from SEM images we deduce that the inverse opal is mechanically and thermally stable after laser processing. Moreover, reflectance measurements show that optical properties are also maintained. From these results, we can conclude that inverse opal fabrication is compatible with solar cell technology and that contacts can be created by laser means without damaging the surrounding 3D inverse opal structure neither the silicon below it.
\end{abstract}

Keywords: Inverse opals, solar cell, electrospray, laser contact, photonic crystal.

\section{Introduction}

Nowadays, one of the main strategies to decrease the cost of crystalline silicon (c-Si) solar cells is reducing the quantity of silicon material by using thinner c-Si wafers. If possible, the formation of random pyramids on c-Si surface is a solution hard to beat due to its cost-effectiveness, compatibility with industrial environments and very good optical response. However, alternative light trapping schemes for thin silicon solar cells, either amorphous or crystalline, have been proposed and their optical properties assessed [1-6]. In all these studies, a trade-off between optical enhancement and electrical losses arises. At the same time, photonic structures (opals layers) had been integrated as intermediate back-reflector for micromorph devices tandem silicon solar cells with amorphous silicon front absorber and a microcrystalline silicon bottom absorber [7,8], showing the increasing importance of light trapping for many types of thin solar cells.

Apart from their optical response, other technical issues must be addressed for a successful introduction of the photonic structure into finished devices. Particularly, when the photonic structure is applied to the rear side

\footnotetext{
* Corresponding author. Tel.: +34 93 4015681; Fax:+34 934016756
} 
of the solar cell, the c-Si base has to be contacted through it in order to extract the photogenerated carriers. Among all the technological solutions, laser firing has demonstrated to be a reliable technique to contact through dielectric solid thin layers $[9,10]$.

This paper focuses on the viability of $\mathrm{Al}_{2} \mathrm{O}_{3}$ inverse opals to improve back reflector of c-Si solar cells. In figure 1 , we show the hypothetical solar cell with the inverse opal integrated into the rear surface. The superiority of this rear reflector compared to double side random pyramids is beyond the scope of this paper and must be studied in detail taking into account the c-Si substrate characteristics and technological constraints. The present research focuses on the compatibility problems associated with the fabrication and integration of the photonic structure while keeping the electrical and mechanical properties of the original solar cell. In particular, we study the use of laser firing to create contacts through $\mathrm{Al}_{2} \mathrm{O}_{3}$ inverse opals..

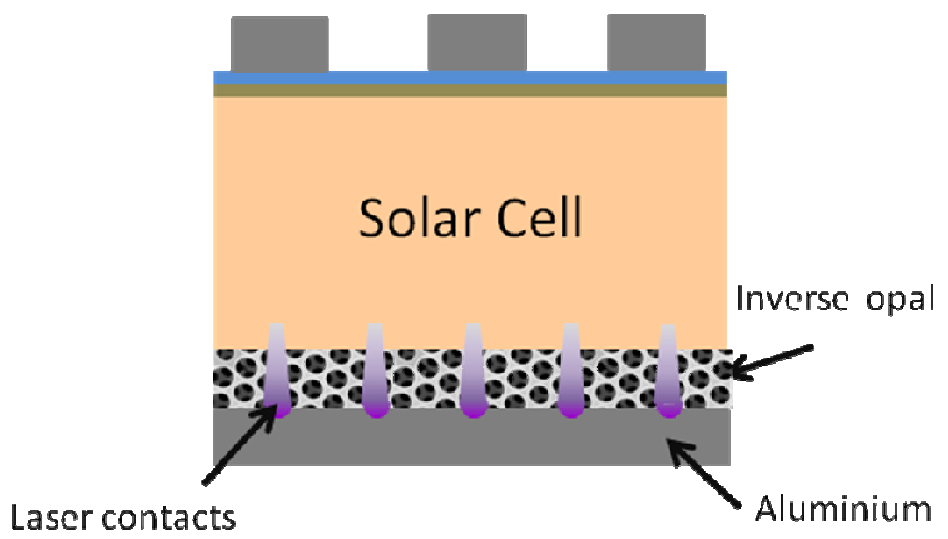

Figure 1. Solar cell Structure: Schematic description of the solar cell structure used in the experiments

For the inverse opal formation, we use colloidal crystals defined by electrospray deposition technique as scaffolds [11-13]. This technique is able to create colloidal crystals in the $\mathrm{cm}^{2}$ range becoming a good choice if the photonic structure has to be applied to commercially relevant devices. In this work we check out the effect of the technique on the surface passivation properties provided by a dielectric film previously deposited onto the c-Si surface We study then the effect of the $\mathrm{Al}_{2} \mathrm{O}_{3}$ deposition and the typical annealing ( $350{ }^{\circ} \mathrm{C}$ for 2 hours) used for nanoparticles burning. In the second part of the paper, we analyse the viability of creating contacts to the c-Si through the inverse opal by means of a laser beam. In particular, In order to ensure the mechanical stability of the inverse opal a group of laser fired samples is studied using SEM (Scanning Electron Microscopy) micrographs and trenches are drilled using FIB (Focused Ion Beam) to check out the morphology of 3D structure at the edge of the laser holes. Finally, reflectance measurements are done before and after laser processing.

\section{Experimental}

To reproduce the rear surface configuration of the hypothetical solar cell (see figure 1) in a c-Si wafer, we start with a complete RCA cleaning of the p-type c-Si substrates. Next, we symmetrically cover them by a $5 \mathrm{~nm} \mathrm{Al}_{2} \mathrm{O}_{3}$ layer at $200{ }^{\circ} \mathrm{C}$ by Atomic Layer Deposition (ALD) technique in order to electrically passivate c$\mathrm{Si}$ surface. Then, samples are annealed at $400^{\circ} \mathrm{C}$ for 10 minutes in order to activate the fixed charge density located at the $\mathrm{Al}_{2} \mathrm{O}_{3} / \mathrm{c}$-Si interface and improve surface passivation. In the next step, $\mathrm{Al}_{2} \mathrm{O}_{3}$ is etched using diluted HF in a small region of the sample to have access to the silicon. The sample is then introduced into the 
electrospray setup where the bare c-Si area is used to apply a negative bias of $-1000 \mathrm{~V}$ to the sample while a positive polarization of $5000 \mathrm{~V}$ is applied to a needle from where a nanofluid $(360 \mathrm{~nm}$ diameter polystyrene nanoparticles) is expulsed. This technique creates a $\sim 1 \mathrm{~cm}^{2}$ colloidal crystal on top of the $\mathrm{Al}_{2} \mathrm{O}_{3}$ passivating film that will be used as a scaffold for the future inverse opal. After the electrospray step, samples are brought to the ALD reactor again to grown a $20 \mathrm{~nm}$ conformal layer of $\mathrm{Al}_{2} \mathrm{O}_{3}$ that fills all the gaps between the polystyrene nanoparticles. All the chemical reactions take place in a small vacuum chamber at $80^{\circ} \mathrm{C}$ to prevent melting of the polystyrene nanoparticles. Finally the samples are heated up to $350^{\circ} \mathrm{C}$ with a ramp of $5^{\circ} \mathrm{C} / \mathrm{min}$ and keeping the maximum temperature for 2 hours so as to burn the polystyrene nanoparticles. Inverse opals are also created onto glass substrates for optical characterization following the same steps but starting with a glass substrate covered with ITO (Indium Tin Oxide) that is used as an electrode for the electrospray deposition of the nanoparticles. By SEM observation, we verify that the morphological properties of the inverse opals fabricated on glass samples are identical to the ones fabricated on silicon substrates. In order to check the mechanical and optical damage produced by the laser, silicon and glass samples are laser processed using a 1064nm $400 \mathrm{~ns}$-pulse Nd:Yag laser. Holes are drilled using a square matrix of laser dots created with a laser power of $0.8 \mathrm{~W}$ and with a distance of $250 \mu \mathrm{m}$ between them.

\section{Results and discussion}

First of all, we checked out the stability of the electrical c-Si surface passivation through all the steps of the fabrication of the inverse opals by measuring the effective lifetime $\left(\tau_{\text {eff }}\right)$ of the sample. From these values, an upper limit of the effective surface recombination velocity $\left(S_{\text {eff }}\right)$ can be calculated using $S_{\text {eff }}<w / 2 \tau_{\text {eff }}$, where $w$ is the wafer thickness. In this expression we assume that both surfaces have the same recombination rate and that no recombination takes place at the c-Si bulk. The values obtained after each step of the fabrication process are shown in table 1 . As it can be observed, surface passivation quality is excellent in all cases with $S_{\text {eff }}$ values well below $10 \mathrm{~cm} / \mathrm{s}$. Interestingly, it must be mentioned that after applying the electrospray process the $S_{\text {eff }}$ values slightly increase. However, the subsequent thermal steps needed for the fabrication of the inverse opal help to recover part of the passivation quality. In any case, electrical passivation is maintained to $S_{\text {eff }}$ values that allow the fabrication of high-efficiency c-Si solar cells [14].

\begin{tabular}{|c|c|c|c|}
\hline$\tau_{\text {eff }}(\mathrm{ms}) / \mathrm{S}_{\text {eff }}(\mathrm{cm} / \mathrm{s})$ & Initial $5 \mathrm{~nm} \mathrm{Al}_{2} \mathrm{O}_{3}$ & Electrospray & $\mathrm{Al}_{2} \mathrm{O}_{3}+350^{\circ} \mathrm{C} 2$ hours \\
\hline sample 1 & $6.3 / 2.25$ & $2.49 / 5.68$ & $3.25 / 4.35$ \\
\hline sample 2 & $4.57 / 3.10$ & $2.09 / 6.77$ & $2.65 / 5.34$ \\
\hline sample 3 & $5.15 / 2.75$ & $1.6 / 8.84$ & $2.83 / 5$ \\
\hline
\end{tabular}

Table 1. Evolution of the passivation properties of $\mathrm{Al}_{2} \mathrm{O}_{3} / \mathrm{c}-\mathrm{Si}$ interface through the inverse opal fabrication process.

After demonstrating the fabrication of inverse opals without any detrimental effect on surface passivation, we focus on the contact formation to the c-Si base by means of a laser beam. Regarding the mechanical stability, we have performed systematic SEM observations of the holes drilled by laser on silicon samples. Typical obtained images are shown in Figure 2. As shown in figure 2,A) and 2,B), the holes drilled in the 
inverse opal structure have 50-60 $\mu \mathrm{m}$ diameter corresponding to the usual diameter found in the laser spots produced by this laser onto the same dielectric [15]. As it can be observed, surrounding the laser spot there is a circular $25 \mu \mathrm{m}$-wide area where the top of the inverse opal has been blown up, probably by the gases produced during the melting of the materials and trapped inside the structure. However, the rest of the layers below that one are not affected as revealed by the FIB trench shown in figure 2,C) where the worst case scenario, i.e. the thinner colloidal crystal produced by the electrospray method (7 layers), is analyzed. Therefore, the mechanical stability of the inverse opal on silicon is confirmed.

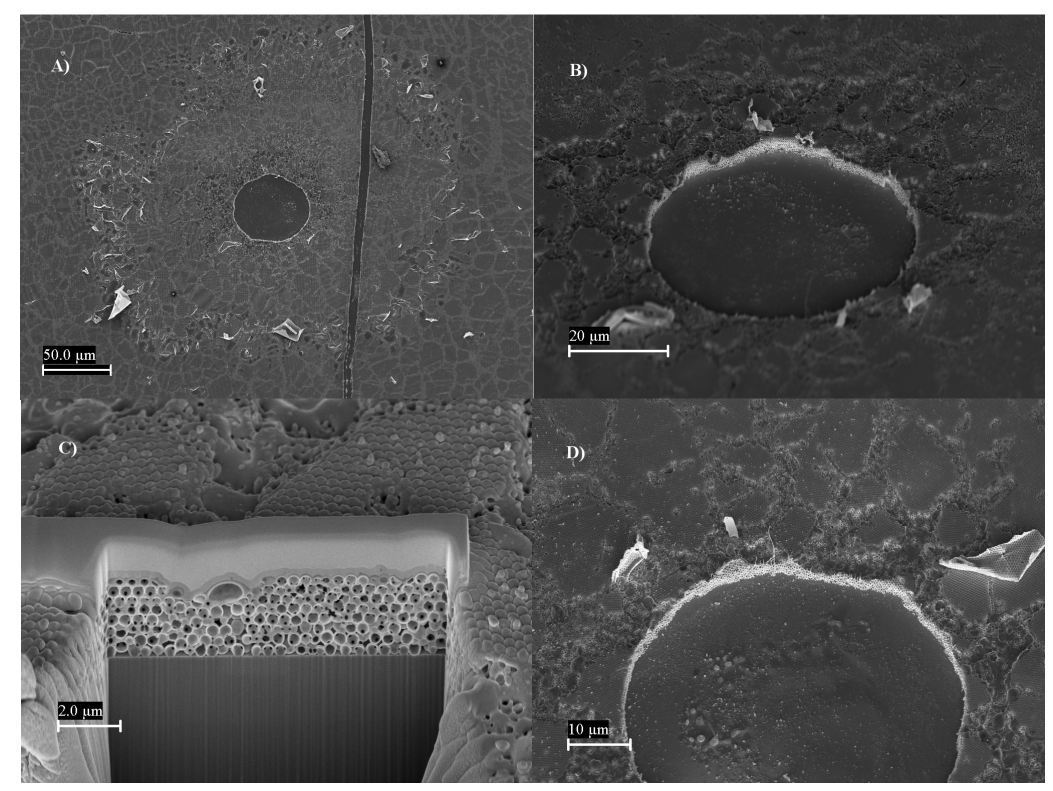

Figure 2. Laser processed $\mathrm{Al}_{2} \mathrm{O}_{3}$ inverse opal on silicon $\mathrm{SEM}$ pictures showing laser holes through the inverse opal structures on silicon A) B) C) D)

From the point of view of the optical properties, we show in figure 3 the reflectivity of the inverse opal on silicon sample showing a peak of $72 \%$ at $\lambda=690 \mathrm{~nm}$. The laser processed inverse opal on glass is also shown with a very similar reflectivity response. In this case, the peak is located at $\lambda=700 \mathrm{~nm}$ and its reflectivity value is $69 \%$ demonstrating that the laser process keeps the photonic properties of the inverse opals. Based on the previous results where the mechanical properties have been maintained after laser processing, the difference between both cases could be related to the laser processed area fraction which is $3.1 \%$. In any case, the optical properties of the inverse opals are not jeopardized by the contact formation. The wider reflectance peak of the inverse opal on c-Si compared to the one on glass is attributed to a worse quality of the photonic crystal probably related to the fact that the samples were produced with different batches of nanoparticles.

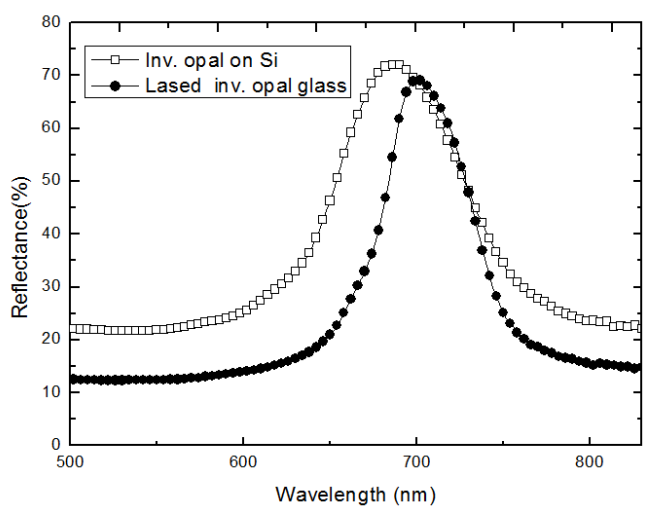


Figure 3. Reflectance measurements. Measurements corresponding to $\mathrm{Al}_{2} \mathrm{O}_{3}$ inverse opal on silicon and on glass after laser processing. The plot shows no remarkably difference between both signals.

\section{Conclusions}

A photonic structure has been fabricated and characterized as a suitable back reflector for c-Si solar cells. This structure consists on an $\mathrm{Al}_{2} \mathrm{O}_{3}$ inverse opal based on a colloidal crystals deposited by electrospray. First of all, we check out that the fabrication of the photonic structure does not negatively impact on the surface passivation provided by a dielectric film previously deposited onto c-Si surface. $S_{\text {eff }}$ values below $10 \mathrm{~cm} / \mathrm{s}$ are measured paving the way to high-efficiency solar cells. Once this requirement is fulfilled, we focus on mechanical and optical properties after creation of the contacts through the photonic structure by means of a laser beam. SEM images show that the inverse opal is mechanically stable after the laser drilling process. Finally, optical measurements do not show significant reflectance degradation after the laser process. With all these results, we can conclude that the production of inverse opals in the way proposed hereby is compatible with the fabrication of high-efficiency c-Si solar cells as electrospray setup is easily scalable to cover large areas in the $\mathrm{cm}^{2}$ range [16].

\section{Acknowledgements}

This work has been partially supported by the Spanish Ministry of Science and Innovation under projects TEC2011-26329 and the Network of Excellence 'Nanophotonics for Energy' GA 248855. SEM and optical measurements have been performed at CRNE (Centre de Recerca en Nanoenginyeria). The authors thank Dr. Trifon Trifonov for his helpful discussions.

\section{References}

[1] S. Mokkapati, and K. R. Catchpole, Nanophotonic light trapping in solar cells, Journal of Applied Physics, 112, 101101 (2012), DOI:http://dx.doi.org/10.1063/1.4747795

[2] P. Bermel, C. Luo, L. Zeng, L. Kimerling, and J. Joannopoulos, "Improving thin-film crystalline silicon solar cell efficiencies with photonic crystals," Opt. Express 15, (2007),16986-17000.

[3] L. T. Varghese, Y. Xuan, B. Niu, L. Fan, P. Bermel and M. Qi, "Enhanced Photon Management of Thin-Film Silicon Solar Cells Using Inverse Opal Photonic Crystals with 3D Photonic Bandgaps”, Advanced Optical Materials, 1, (2013), $692-698$.

[4] C. Battaglia, C.-M. Hsu, K. Söderström, J. Escarré, F.-J. Haug, M. Charrière, M. Boccard, M. Despeisse, D. T. L. Alexander, M. Cantoni, Y. Cui, C. Ballif, Light Trapping in Solar Cells: Can Periodic Beat Random?, ACS Nano, 6, (2012)

[5] U. W. Paetzold, M. Smeets, M. Meier, K. Bittkau, T. Merdzhanova, V. Smirnov, D. Michaelis, C. Waechter, R. Carius, U. Rau, Disorder improves nanophotonic light trapping in thin-film solar cells, Applied Physics Letters, 104, ( 2014) 
[6] V. Narasimhan, Y. Cui, Nanostructures for photon management in solar cells. Nanophotonics, 2(3), (2013), 161-240. doi:10.1515/nanoph-2013-0001

[7] J. Üpping, A. Bielawny, R. B. Wehrspohn, T. Beckers, R. Carius, U. Rau, S. Fahr, C. Rockstuhl, F. Lederer, M. Kroll, T. Pertsch, L. Steidl, R. Zentel, Three-Dimensional Photonic Crystal Intermediate Reflectors for Enhanced Light-Trapping in Tandem Solar Cells, Advanced Materials, 23, (2011).

[8] A. Bielawny, J. Üpping, P. T. Miclea, R. B. Wehrspohn, C. Rockstuhl, F. Lederer, M. Peters, L. Steidl, R. Zentel, S.-M. Lee, M. Knez, A. Lambertz, R. Carius, 3D photonic crystal intermediate reflector for micromorph thin-film tandem solar cell, physica status solidi (a), 205, (2008).

[9] I . Martín, P . Ortega, M . Colina, A. Orpella, G. López, R. Alcubilla. Laser processing of Al2O3/a-SiCx:H stacks: a feasible solution for the rear surface of high-efficiency p-type c-Si solar cells. Progr. Photov.: Res. Appl. ,21, (2013), 1171-1175.

[10] P. Ortega, I. Martín, G. Lopez, M. Colina, A. Orpella, C. Voz, R. Alcubilla. p-type c-Si solar cells based on rear side laser processing of Al2O3/SiCx stacks, Solar Energy Materials and Solar Cells, 106 (2012), 80-83.

[11] A.Coll, S.Bermejo, D.Hernández, L.Castañer, Colloidal crystals by electrospraying polystyrene nanofluids. Nanoscale Research Letters 8 (2013), 26- . doi:10.1186/1556-276X-8-26

[12] Patent: WO 2013001128 A1, "Procedimiento para el depósito ordenado de capas de metamateriales a partir de soluciones coloidales de micro o nano esferas p201131081”, Luis Castañer, Sandra Bermejo and Arnau Coll 27 Feb 2013.

[13] A. Coll, S. Bermejo, L. Castañer, Self-assembly of ordered silica nanostructures by electrospray, Microelectronic Engineering, 121,(2014), 68-71, http://dx.doi.org/10.1016/j.mee.2014.03.031.

[14] A. G. Aberle, Surface passivation of crystalline silicon solar cells: a review, Progress in Photovoltaics: Research and Applications, 8 (2000), 473-487.

[15] I. Martín, P. Ortega, M. Colina, A. Orpella, G. López and R. Alcubilla, Laser processing of $\mathrm{Al}_{2} \mathrm{O}_{3} / \mathrm{a}-\mathrm{SiC}_{\mathrm{x}}: \mathrm{H}$ stacks: a feasible solution for the rear surface of high-efficiency p-type c-Si solar cells, Progress in Photovoltaics: Research and Applications, 21 (2013), $1171-1175$.

[16] R. Bocanegra, D. Galána, M. Márquez, I.G. Loscertalesd, A. Barrero, Multiple electrosprays emitted from an array of holes. J. Aerosol Sci. 36 (2005)1387-1399

\author{
Acknoledgment: \\ Journal "Microelectronic Engineering"
}

Access to published paper:

http://www.sciencedirect.com/science/article/pii/S0167931715000891

DOI: $10.1016 /$ j.mee.2015.02.037 